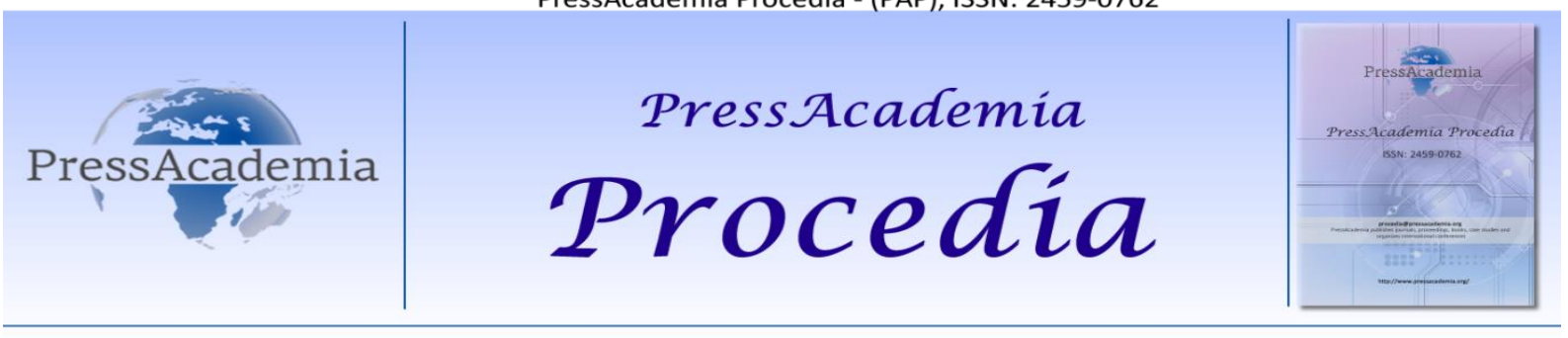

Global Business Research Congress (GBRC), May 24-25, 2017, Istanbul, Turkey

\title{
A TYPOLOGY FOR P2P ACCESS BASED EXCHANGES IN MARKETPLACES
}

\author{
DOI: 10.17261/Pressacademia.2017.648 \\ PAP- GBRC-V.3-2017(74)-p.716-722
}

Can Ülker ${ }^{1}$, Şebnem Burnaz ${ }^{2}$

${ }^{1}$ Istanbul Technical University, Faculty of Management Engineering, Maçka Campus, 34367 Beşiktaş, Istanbul, Turkey ulkerca@itu.edu.tr

${ }^{2}$ Istanbul Technical University, Faculty of Management Engineering, Maçka Campus, 34367 Beşiktaş, Istanbul, Turkey burnaz@itu.edu.tr

To cite this document

Ulker, C and S. Burnaz (2017). A typology for p2p access based exchanges in marketplaces. PressAcademia Procedia (PAP), V.3, p.716-722.

Permemant link to this document: $\mathrm{http}: / /$ doi.org/10.17261/Pressacademia.2017.648

Copyright: Published by PressAcademia and limited licenced re-use rights only.

\section{ABSTRACT}

Different business models, products and services that are introduced with the advances in digital technologies and Internet gave rise to alternative modes of consumption. Along with this shift from ownership-based to an access based consumption, a stream of scholarly research has focused on different aspects of alternative modes of consumption such as sharing, gift giving, collaborative consumption, etc. to explain the emerging phenomena. Although several conceptualizations can be found in the literature, there is still a gap in the academic knowledge about peer-to-peer (P2P) sharing and its content. Products and services subject to sharing may vary from a car that is shared for a ride by the owner with a passenger in return for an economic benefit -so called ridesharing-, or a house that is owned by an individual and made available for rental of other people -as in Airbnb-. As the notion of exchange differs significantly between various business models based on access based P2P exchanges, this creates new possibilities to redefine the concept. This study compares access based P2P exchanges with market-mediated access-based consumption (Bardhi and Eckhardt, 2012) and sharing (Belk, 2007), and offers a typology based on the level of transfer of ownership and economic nature of perceived value. Real life business models are presented based on this typology and further research directions are suggested to better understand the main motivations of consumers for choosing an access based P2P model rather than conventional options available in the market.
\end{abstract}

Keywords: Sharing, collaborative consumption, exchange, internet, peer-to-peer JEL Codes: M3, M31

\section{INTRODUCTION}

Especially with the introduction of Web 2.0, which empowers users to participate in content creation and direct connection between each other compared to the one-directional information supply of its ancestor Web 1.0 (Belk, 2014), recent years have witnessed an increasing trend towards adoption of business models that facilitate access rather than ownership. As stated by Möhlmann (2015), growing number of people are engaging in car sharing, bicycle sharing or accommodation rental through the usage of Internet. It is clearly seen that consumer preferences and exchange patterns are undergoing a transformation because of the shift from an individualistic-oriented consumption to a collaborative one (Albinsson and Perera, 2012). This new pattern of consumption is generally described as "collaborative consumption" (Botsman and Rogers, 2010), although different classifications such as "access based consumption" (Bardhi and Eckhardt, 2012) or "product service systems" (Catulli et al., 2013) are also used in the literature. These consumption patterns can be generalized under the main label of alternative modes of consumption, along with other concepts such as anticonsumerism or political consumerism. This conceptual paper will review the literature on sharing and collaborative consumption and compare the notion of exchange for peer-to-peer (P2P) exchanges of material possessions such as sharing a car for a ride, clothes or flats, with other access based consumption models cited in the literature. The main outcome of the study is the presentation of a typology for P2P exchanges based on two dimensions which are argued to be focal for the concept: the transfer of ownership and the economic nature of perceived value. 


\section{LITERATURE REVIEW ON SHARING AND COLLABORATIVE CONSUMPTION}

\subsection{Sharing and Self}

Although dating back until archaic societies (Belk, 2010), sharing has gained interest from scholars during the last decade especially because of the rise in alternative business models that emerged with the advances in Internet and online technologies. Sharing is defined by Belk (2007) as "the act and process of distributing what is ours to others for their use and/or the act and process of receiving or taking something from others for our use". Therefore, it differs from both gift giving and commodity exchange since the latter ones are one-way economic transfers as explained by Belk (2010) in his seminal work emphasizing the difference of sharing clearly. In both gift giving and commodity exchange, there are parts to the exchange which look for reciprocity (Sahlins, 1972) by keeping track of the balance between giving and receiving or buying and selling. Sharing, on the other hand, is considered as a communal act that bonds people together. A prototype of sharing can be seen in mothering, or allocation of resources within a family where no reciprocity or exchange is sought (Belk, 2010).

Contrary to the contemporary consumer behavior that is characterized by economics-based marketplace exchanges, sharing indicates an unequal exchange characterized by one side's ability to share to satisfy one other's need (Albinsson and Perrera, 2012). It is an exchange that is directly related to the extended self (Belk, 1988). As an extension to self's embodiment and thoughts, material things or possessions make up the extended self (Belk, 2013). Consumers identify themselves with their possessions in ownership, which become a part of their extended selves (Bardhi and Eckhardt, 2012). Although ownership relates to the notion of extended self, humans share their possessions under different circumstances. Most commonly, sharing takes place within family or between close kin and friends, where it becomes an inclusive act of "sharing in" that is aggregating the extended self (Belk, 2014). Although much sharing happens within family or people that self has strong ties with (Granovetter, 1973), there are examples of sharing possessions with relative strangers, such as sharing a lighter with someone who tries to light a cigarette. Such circumstances are defined as "sharing out", where sharing is intended to be a one-time act that doesn't imply inclusion of others to the extended self (Belk, 2014). Although explaining mainly offline sharing behavior, these concepts have been revisited with the rise of Internet-facilitated sharing environments (Belk 2010, Belk 2013, Belk 2014). In its very nature, Internet is an extensive source of information, knowledge and content that is open to access of anyone who has the required infrastructure. Most of this huge amount of content is free to access, download or share. Therefore, notion of extended self, possessions and sharing on Internet differ from the offline world (Belk, 2013). Belk suggests that dematerialization of possessions leads to changes in the sense of ownership and attachment to the possession, which increases the sharing of digital possessions such as music collections or photos. This kind of sharing resembles "sharing out", where people that are accessing the music collection or photos are not seen as a part of extended self (Belk, 2013).

\subsection{Collaborative Consumption}

Apart from the sharing of immaterial possessions, Internet facilitates the transfer or use of material goods between consumers (Belk, 2014). Online sharing services such as car sharing service ZipCar or short term room rental service Airbnb are some examples of how material goods are shared between consumers with the use of Internet. As sharing of these material goods generally include an economic exchange between supplier of the good and consumer, they possess a whole different type of consumption pattern, referred as "collaborative consumption" (Botsman and Rogers 2010, Belk 2014). Although it seems to be recently a prevalent subject, collaborative consumption was actually first defined in 1978 as "events in which one or more persons consume economic goods or series in the progress of engaging in joint activities with one or more others" (Felson and Spaeth, 1978). In this definition, people watching a football game are also considered to engage in collaborative consumption. However, this definition does not include any definitive guide to transfer of ownership, whereas it is a central topic for contemporary collaborative consumption patterns since the introduction of new service and business models that reduce personal consumption (Albinsson and Perera, 2012). Belk (2014) adds this concept to the definition and argues that collaborative consumption is "people coordinating the acquisition and distribution of a resource for a fee or other compensation" (Belk, 2014). Simply with this definition, gift giving is excluded from collaborative consumption as it involves a transfer of ownership and collaborative consumption sits in the middle ground between sharing and marketplace exchange, including elements from both.

Bardhi and Eckhardt (2012) termed the similar concept as access-based consumption, by defining it as "transactions that may be market mediated in which no transfer of ownership takes place" (Bardhi and Eckhardt, 2012). Here the emphasis is on access that implicitly suggests no transfer of ownership. Namely, it includes a provision where an integrated product and service is acquired by a user as a service with renting or leasing, resulting with that product or service being shared with other consumers (Catulli et al., 2013). Specifically, the market mediated side of access based consumption implies a premium price that is paid by consumer for the use of the object and the service that is given by a company. However, a 
premium price is not required for collaborative consumption, such as free exchange sites or redistribution markets where consumers don't have to pay a price to gain access to the product (Albinsson and Perera, 2012). Therefore, collaborative consumption is more of a subset of access-based consumption which specifies a market-mediated access (Belk, 2014). Subject to a diverging research stream, product service systems are also identified by Catulli et al. (2013) as integrated systems which "consumers can access the use of, without acquiring the ownership of it, that is, supplied on an access basis" (Catulli et al., 2013). Here a distinction should be drawn between product service systems and access-based consumption. The former introduces a system level approach to access; whereas the latter is a form of consumer behavior. Product service systems can be product-oriented, use-oriented or result-oriented. They are characterized by ownership, providing of a function while retaining the ownership and replacing the product with services respectively. Thus, product is a supporting supplier of the service in this case (Catulli et al., 2013).

Although the research studies explaining the nature of collaborative consumption are increasing, there is still a gap in the understanding of peer-to-peer (P2P) exchanges. P2P exchanges are based on one individual making her physical possession temporarily available to meet someone else's temporary need in return of mainly economic utilities, without a transfer of ownership (Philip et al., 2015). As exchanges where ownership is not transferred are radically different than those that include transfer of ownership (Loveluck and Gummesson, 2004), P2P exchanges differ from other consumption practices. This paper aims to shed light on the notion of ownership and economic benefit in P2P access based marketplace exchanges. A typology for P2P exchanges is proposed based on two dimensions; level of ownership transfer and the economic nature of perceived value. This focus is deliberately chosen to find an explanation to why consumers started to prioritize experience of doing, seeing and feeling over owning stuff (Euromonitor, 2016). After the presentation of our typology, the explanation will be expanded by integrating the discussion of real business model examples.

\section{P2P EXCHANGE IN COLLABORATIVE CONSUMPTION MODELS}

Exchange has been a central subject matter for the marketing concept since the early 1970s. Market based transactions were the antecedents of the exchange concept, where mainly economic exchange of goods and services were studied in marketing literature (Luck, 1969). The exchange concept was then "broadened" with the inclusion of nonprofit organizations (Kotler and Levy, 1969), and ultimately a generic concept was proposed to include all transactional activities for the exchange (Kotler, 1972). Since then, exchange has been a focal point of interest in the marketing literature and commonly regarded as the transfer of tangible or intangible entities between two parties (Bagozzi, 1975). With the rise of the Internet, new forms of exchange have been introduced especially with the introduction of alternative modes of consumption. Peer-to-peer (P2P) exchange is one of these forms, which is typically visible in collaborative consumption or access based consumption models. Although consumers previously could have exchanged goods, P2P exchange typically happens directly between two parties who are empowered by Internet and other related infrastructure to make this transaction by removing most of the traditional elements of the value chain (Plouffe, 2008). Thus, P2P exchange may hold an access nature rather than ownership. This leads us to a dimension that should be explained regarding the transfer of ownership between different business and service models. While there are differing levels of transfer of ownership from the owner to other party who is seeking access, expected economic benefits of renting or disposing also may vary. Therefore, level of ownership transfer and economic nature of perceived value are chosen to explain the distinctive nature of P2P exchanges.

\subsection{Level of Ownership Transfer}

For an access based P2P exchange to happen, one part of the exchange should be the holder of the possession, so that this good can be shared (Belk, 2007). In the specific case of access based P2P exchange, the one who is holding possession is the supplier of the service for the one who is seeking to gain access. Thus, P2P exchanges fundamentally imply ownership. Consequently, motivations underlying the sharing behavior should be treated separately for the owner or supplier, and the one who is seeking access. Possessions are not just seen as a part of the extended self (Belk, 1988), but they also project an image of status, help to express consumer's self-identity and have affective dimensions to the extent that their loss is seen as tragedy (Catulli et al., 2013). However, in P2P exchanges owners of the possessions are inclined to share what they possess. Sharing can range from clothes as in swaps to properties as in P2P room rental. As suggested by Belk (2007), sharing of tangible objects is an extended version of keeping-while-giving motivation, which is generally identified with intangible objects. People tend to share the things that are unlimited in supply, whereas they try to retain possession when there is a sense of scarcity (Belk, 2007). In the case of ridesharing, this holds true as the car already heading to a direction is an unlimited supply in the eyes of the driver, who prefers sharing this unexploited resource with a passenger. However, differently, temporary transfer of ownership happens in the case of Airbnb (Philip et al., 2015). As a result, level of ownership transfer could be considered as differentiating dimension between access based P2P exchange models. 


\subsection{Economic Nature of Perceived Value}

Traditionally, sharing lacks reciprocity when it is treated as "sharing in" that happens within the family (Belk, 1988). Previous research has found that for the ones who prefer an access based consumption in a B2C car sharing context rather than owning a car; there is strong evidence for negative reciprocity, where individuals acted in their self-interest (Bardhi and Eckhardt, 2012). This is argued to be not the case for access based consumption of nursery and baby equipment (Catulli et al., 2013). It can be discussed that consumers set higher expectations from a B2C car sharing service, because they communicate directly with a brand. However, economic exchange happens directly between peers in a P2P exchange; which can be associated with a balanced reciprocity. From this perspective, sharing of possession has more of an economic utilitarian aspect as owner benefits economically from this exchange. Users who prefer collaborative consumption are predominantly driven by rational reasons (Möhlmann, 2015) and they are mostly utilitarian (Bardhi and Eckhardt, 2012). This usually holds true for access based P2P exchange. The owner seeks to gain extra money by exploiting a resource that is idle and consumers seek to maximize the value for money. However, both owners and consumers have other aspects to enhance the value that is exchanged in an access based P2P exchange apart from the obvious economic reasons, which affect the balance of reciprocity. Ease and convenience of the transaction based P2P system is a mediating factor for the one who is demanding the service (Plouffe, 2004). Hennig-Thurau, Henning, and Sattler (2007) suggest that consumers are more likely to choose a sharing option when owning and sharing are perceived as having equal product benefits (HennigThurau et al., 2007). On the other hand, Chen (2009) found that hedonic aspects affect perceived value for art visitors who prefer to visit the exhibitions rather than collecting the pieces (Chen, 2009).

In an access based P2P exchange, both sides create a transactional social connection with each other, for example by sharing the ride together, adding a hedonist dimension to the exchange. This also fosters the sense of community (Albinsson and Perera, 2012). Ozanne and Ballentine (2010) found that a group of users who use shared toy libraries enjoy social benefits and a form of "sharing in" as an expression of community. Besides, establishing an identity as a smart and savvy consumer, realizing a lifestyle that can't be afforded by ownership and getting rid of the single identity that is restricted by ownership are sign values that are found in consumers that engage in access based consumption (Bardhi and Eckhardt, 2012). Finally, social and environmental causes are evident in access based P2P exchanges compared to other modes of collaborative consumption. Choosing access over ownership is used as a way by consumers to show ideological interests to society, business and government. Such choice is practiced as a revolution against the dominant marketplace and its abusive practices (Bardhi and Eckhardt, 2012). Users of access options seem to hold socially responsible believes which are argued to be lifting factors for the adoption of access based consumption (Catulli et al., 2013). Especially, choosing an access based P2P exchange can be explained with social responsibility. It is an effective use of resources for both parties in the exchange. Although there are other alternatives to satisfy the same need, consumers prefer engaging in $\mathrm{P} 2 \mathrm{P}$ exchange to create social and environmental benefits. To summarize, both economic and non-economic benefits affect the perceived value of choosing a P2P exchange alternative. Therefore, economic nature of perceived value is also a differentiator between P2P exchange models.

\section{PROPOSED TYPOLOGY FOR P2P EXCHANGE MODELS}

Based on the discussions given in the above sections, a typology for access based P2P exchanges is offered. The level of ownership transfer and the economic nature of perceived value are used as two dimensions differentiating types of exchanges. High level of ownership transfer means that the resource is accessed individually by the one who seeks access. Low level of ownership transfer suggests that the resource is not physically shared by the owner, and the one who accesses the resource uses the service simultaneously with the owner. It should be noted that this differentiation is not directly same with the definitions of ownership transfer; here, the focus is rather on the temporariness of transfer of ownership.

In addition to the transfer of ownership, economic benefits are another dimension for the proposed framework. Economic nature of perceived value is high when the main contributor to the perceived value of P2P exchange is economic benefits. On the other hand, it is low when economic benefits are not the dominant reason of engaging in a P2P exchange. This dimension is expected to have more explaining power about the behavior of owner of the shared resource, as people who seek access undoubtedly enjoy economic benefits compared to ownership. Figure 1 shows the typology of P2P exchanges and real-life examples for each quadrant, which are examined in more details in following sections. 
Figure 1: Proposed Typology and Examples for P2P Exchange Models

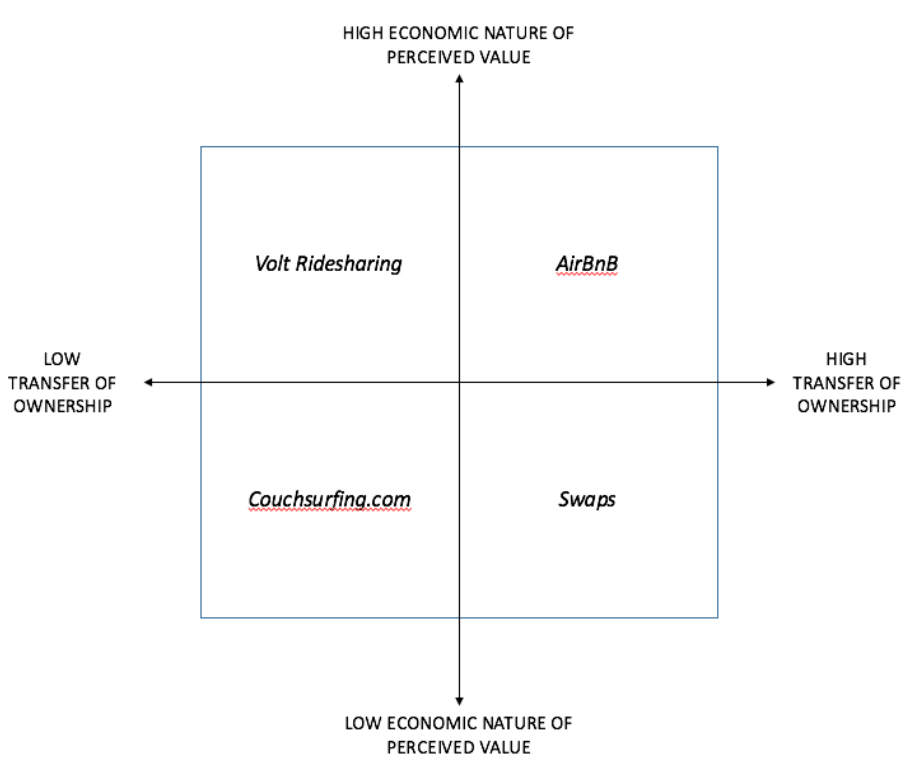

Low Transfer of Ownership / High Economic Nature of Perceived Value

For some of the access based P2P models, economic utilities dominantly drive the choice of engaging in a P2P exchange while transfer of ownership is low. This is the case for ridesharing, an alternative mode of transportation which matches drivers and passengers that are going in the same direction. Volt is an example that is operating in Istanbul focusing on inner-city ridesharing. This system matches drivers who are already heading to a direction with passengers that can join them. It offers daily commutes that are $70 \%$ cheaper than taxi for passengers. Another example is BlaBlaCar, which covers inter-city travel and positions itself as an alternative for bus or train trips. It also offers a convenient way for travelers by offering comfort of a car with a much lower cost. For both examples, ownership of transfer is low as driver and passenger share the ride experience. However, drivers earn money because of this P2P exchange and are mainly economically driven to cover their costs of using and maintaining a car. Although perceived value increases with social interaction and balanced reciprocity is argued to be dominant, main driver for the P2P exchange is economic. Thus, perceived value is highly economically driven. In this concept, sharing out is the prototype for initial P2P exchange. It can be argued whether the passenger is included to the extended self or a sense of community is immediately created after the sharing of experience.

\section{Low Transfer of Ownership / Low Economic Nature of Perceived Value}

In this P2P exchange model, resource access is simultaneously done by the owner and the one who accesses. In terms of perceived value, the main motivation to share is not economic utilities. For example, Couchsurfing.com is an open marketplace for travelers to find a place to stay in virtually any place in the world for free. Couchsurfers open their homes for possible demand and host others for free at their own house. Nearly no transfer of ownership is found in this P2P exchange, as hosts accept surfers in their own house and are staying with them at the same time. Both the platform and staying at the host are free, making economic nature of the perceived value low. The reciprocity is balanced with an obligatory feature of the system, which demands couchsurfers to be also available as hosts inside the system. Besides, couchsurfers have a strong sense of community. They realize their lifestyle as travelers by being in this closely-knit community. Although the sharing prototype depicts "sharing in", couchsurfers are usually strangers who stay at each other's house. This can create a potential future research area about assessing the demarcation between "sharing in" and "sharing out" with the rise of alternative consumption patterns and Internet as a facilitator.

\section{High Transfer of Ownership / High Economic Nature of Perceived Value}

When the resource is unavailable for the owner at least for some time, the one who gains access temporarily holds possession. If economic benefits are dominant for engaging in this P2P exchange, this quadrant can be focus. Airbnb as a good example for this kind of P2P exchange, is a P2P online marketplace that enables people to list and rent short-term accommodation. The owner sets the price and rents her place for a desired period to the renter. As examined by Philip et al. (2015), economic utility is the primary consideration for P2P rental of properties. On the other hand, Airbnb users 
commonly express their loyalty to the service. Although Airbnb is only a facilitator or a middleman for the service, users of the platform interestingly show high levels of brand loyalty based on the Best Brands Report (YouGovBrandlndex, 2016). Brand loyalty for online brands that facilitate P2P exchange can be a further research topic, as these business models are increasingly dubbed as the new norm in their respective sectors (Richard and Cleveland, 2016).

\section{High Transfer of Ownership / Low Economic Nature of Perceived Value}

Some P2P exchange models show high transfer of ownership but low economic benefits as in anti-consumption models. Swaps are examples to describe this situation (Albinsson and Perrera, 2012). In swaps, friends and coworkers get together to share used clothes and other goods without even a money exchange. As owner of the clothes engage in temporary disposition, this exchange model also implies a high transfer of ownership. General motives for swaps are rooted in the anti-consumption patterns such as responsible disposition or simplified lifestyles. Thus, perceived value of this P2P exchange is mainly created around socially and environmentally responsible behavior and realizing a lifestyle by being a responsible citizen.

\section{CONCLUSION AND DISCUSSION}

The advent of Internet and advances in digital technologies created unprecedented business models for alternative modes of consumption. Consumption patterns have shifted from an ownership to an access based ones, generating unique but rapidly imitated examples. Although much research has focused on alternative modes of consumption such as collaborative consumption or access based consumption, the literature focusing on access based P2P exchange is still at its infancy. This conceptual paper focuses on the distinctive nature of P2P exchanges in terms of access rather than ownership nature. After an extant literature survey, ownership transfer and economic nature of perceived value dimensions are chosen to offer an explanation for P2P exchanges.

P2P exchanges are compared with other alternative modes of consumption based on the extant literature about sharing, collaborative consumption and access based consumption. General themes in the current body of research are centered around utility, reciprocity and the notion of ownership. However, P2P exchange models differ from other market mediated models. They generally do not imply a transfer of ownership in a traditional sense and perceived value is not always only related to economic utilities. Therefore, P2P exchange models can be examined based on the level of transfer of ownership and the economic nature of perceived value since both two dimensions primarily affect the choice of consumer to engage in a P2P exchange and can be used to explain different access based marketplace models. A typology based on these two dimensions are offered and examples for each cell of the typology framework are given within the context of P2P exchanges.

It is important to understand and distinguish the nature of P2P exchanges as the underlying motivations to engage in this exchange activity are critical to our understanding about choosing a P2P access rather than ownership based consumption. Although traditional consumer behavior focuses on ownership based consumption to satisfy self, alternative access based consumption models using P2P exchange are gaining popularity in the market. Proposed typology is intended to offer an attempt to the classification of and understanding about different access based P2P marketplace models as notion of ownership and economic utility change significantly between these. In further studies, reciprocity can also be used as an alternative dimension to improve this typology as negative, balanced and positive reciprocity sought by P2P exchange partners differs in various business models.

Finally, further research directions may be offered for a thorough understanding of consumer behavior related with these different business models. Firstly, general understanding about the notion of sharing in and sharing out can be discussed further for marketplaces where both transfer of ownership and economic value are low, such as Couchsurfing.com. P2P exchange typically happens face-to-face between two parties without a significant ownership transfer in these models. Expected economic return by the owner is also low because of the non-monetary nature of the marketplace model. It can be argued that owner engages in a sharing in with a stranger, which does not fit our current understanding. Another interesting research realm can be about the exploration of brand loyalty for online P2P exchange marketplaces. Although these models only facilitate the exchange between two parties by taking the role of a middlemen, users show increasing loyalty to the brands even if they get the service or product from peers. Therefore, brand building tools and brand management strategies can be analyzed along with the brand loyalty components especially for these business models. 


\section{REFERENCES}

Albinsson, P. A., and Perera, B. Y. (2012). Alternative marketplaces in the 21st century: Building community through sharing events. Journal of Consumer Behaviour, 11(4), 303-315.

Bagozzi, R. P. (1975). Marketing as exchange. Journal of Marketing, 39(4), 32-39.

Bardhi, F., and Eckhardt, G. M. (2012). Access based consumption: The case of car sharing. Journal of Consumer Research, 39(4), 881-898. Belk, R. (1988). Possessions and the Extended Self. Journal of Consumer Research, 15(2), p.139.

Belk, R. (2007). Why Not Share Rather Than Own?. The ANNALS of the American Academy of Political and Social Science, 611(1), pp.126140.

Belk, R. W. (2010). Sharing. Journal of Consumer Research, 36(5), 715-734.

Belk, R. (2013). Extended Self in a Digital World. Journal of Consumer Research, 40(3), pp.477-500.

Belk, R. (2014). You are what you can access: Sharing and collaborative consumption online. Journal of Business Research, 67(8), pp.15951600.

Botsman, R., and Rogers, R. (2010). What's mine is yours: The rise of collaborative consumption. New York, NY: HarperCollins.

Catulli, M. (2012). What uncertainty?. Journal of Manufacturing Technology Management, 23(6), pp.780-793.

Chen, Y. (2009). Possession and access: Consumer desires and value perceptions regarding contemporary art collection and exhibit visits. Journal of Consumer Research, 35(6), 925-940.

Euromonitor, (2016). The new consumerism: Redefining ownership, values and priorities. Passport.

Felson, M and Spaeth, J.L. (1978), "Community Structure and Collaborative Consumption," American Behavioral Scientist, 21 (March-April), 614-24.

Granovetter, M. (1983). The Strength of Weak Ties: A Network Theory Revisited. Sociological Theory, 1, p.201.

Hennig-Thurau, T., Henning, V. and Sattler, H. (2007). Consumer File Sharing of Motion Pictures. Journal of Marketing, 71(4), pp.1-18.

Kotler, P. (1972). A Generic Concept of Marketing. Journal of Marketing, 36(2), p.46.

Kotler, P. and Levy, S. (1969). Broadening the Concept of Marketing. Journal of Marketing, 33(1), p.10.

Lovelock, C., and Gummesson, E. (2004). Whither services marketing?: In search of a new paradigm and fresh perspectives. Journal of Service Research, 7(1), 20-41.

Luck, D. (1969). Broadening the Concept of Marketing. Too Far. Journal of Marketing, 33(3), p.53.

Möhlmann, M. (2015). Collaborative consumption: determinants of satisfaction and the likelihood of using a sharing economy option again. Journal of Consumer Behaviour, 14(3), pp.193-207.

Ozanne, L. K., and Ballantine, P. W. (2010). Sharing as a form of anti-consumption: An examination of toy library users. Journal of Consumer Behaviour, 9(6), 485-498.

Philip, H., Ozanne, L. and Ballantine, P. (2015). Examining temporary disposition and acquisition in peer-to-peer renting. Journal of Marketing Management, 31(11-12), pp.1310-1332.

Plouffe, C. (2008). Examining "peer-to-peer" (P2P) systems as consumer-to-consumer (C2C) exchange. European Journal of Marketing 42(11/12), pp.1179-1202.

Sahlins, M. (1972). Stone age economics. Chicago, IL: Aldine Atherton.

YouGov BrandIndex (2016), Marketing Week, [online] (Online). Available at: https://www.marketingweek.com/2016/12/16/airbnbstrongest-brand-advocates/ [Accessed 8 May 2017]. 